Pacific Journal of Mathematic 


\title{
A UNIFIED THEOREM ON CONTINUOUS SELECTIONS
}

\author{
E. Michael and C. Pixley
}

\section{A selection theorem is proved which unifies and gene- ralizes some known results.}

1. Introduction. The purpose of this note is to prove the following theorem, which unifies and generalizes previously known results.

THeOREM 1.1. Let $X$ be paracompact, $Y$ a Banach space, $Z \subset X$ with $\operatorname{dim}_{X} Z \leqq 0$, and $\phi: X \rightarrow \mathscr{F}(Y)$ 1.s.c. with $\phi(x)$ convex for all $x \in X-Z$. Then $\phi$ admits a selection.

Recall that a map $\phi: X \rightarrow \mathscr{F}(Y)$, where $\mathscr{F}(Y)$ denotes $\{S \subset Y$ : $S \neq \varnothing, S$ closed in $Y\}$, is lower semi-continuous, or l.s.c., if $\{x \in X$ : $\phi(x) \cap V \neq \varnothing\}$ is open in $X$ for every open $V$ in $Y$. A selection for a map $\phi: X \rightarrow \mathscr{F}(Y)$ is a continuous $f: X \rightarrow Y$ such that $f(x) \in \phi(x)$ for all $x \in X$. Finally, if $Z \subset X$ then $\operatorname{dim}_{X} Z \leqq 0$ means that $\operatorname{dim} E \leqq 0$ for every set $E \subset Z$ which is closed in $X$ (where $\operatorname{dim} E$ denotes the covering dimension of $E)^{1}$.

Theorem 1.1 incorporates several known results: The case $Z=\varnothing$ is [1, Theorem 1], the case $Z=X$ implies [1, Theorem 2], and the case where $Z$ is open in $X$ and $\phi(x)$ is a singleton for all $x \in X-Z$ implies [3, Theorem 1.2] ${ }^{2}$.

The conclusion of Theorem 1.1 can be strengthened to assert that, if $A \subset X$ is closed, then every selection $g$ for $\phi \mid A$ extends to a selection $f$ for $\phi$ : In fact, if we define $\phi_{g}: X \rightarrow \mathscr{F}(Y)$ by $\phi_{g}(x)=$ $\phi(x)$ for $x \notin A$ and $\phi_{g}(x)=\{g(x)\}$ for $x \in A$, then $\phi_{g}$ is l.s.c. by [2, Example 1.3], so $\phi_{g}$ has a selection $f$ by Theorem 1.1, and this $f$ is a selection for $\phi$ which extends $g$.

2. Proof of Theorem 1.1. As in the proofs of the special cases of Theorem 1.1 which were obtained in [1], it will suffice to show that for each $\varepsilon>0$ there exists a continuous $f: X \rightarrow Y$ such that $f(x) \in B_{\varepsilon}(\phi(x))^{3}$ for all $x \in X$. Once that is done, one can obtain the required selection for $\phi$ as the limit of a uniformly Cauchy sequence of continuous functions $f_{n}: X \rightarrow Y$ such that $f_{n}(x) \in B_{1 / n}(\phi(x))$ for all $x \in X$.

${ }^{1}$ Observe that, for normal $X, \operatorname{dim}_{X} Z \leqq 0$ is valid if either $\operatorname{dim} Z \leqq 0$ or $\operatorname{dim} X \leqq 0$.

${ }^{2}$ In the latter two cases, Theorem 1.1 is valid if $Y$ is any complete metric space, since such a space is always homeomorphic to a closed subset of a Banach space.

${ }^{3} B_{\varepsilon}(S)$ denotes the open $\varepsilon$-neighborhood of $S$. 
So let $\varepsilon>0$ be given. For each $y \in Y$, let $U_{y}=\left\{x \in X: y \in B_{\varepsilon}(\phi(x))\right\}$. Then $\left\{U_{y}: y \in Y\right\}$ is an open cover of $X$ because $\phi$ is l.s.c., so there exists a locally finite, open cover $\left\{V_{y}: y \in Y\right\}$ of $X$ with $\bar{V}_{y} \subset U_{y}$ for all $y \in Y$. For each $x \in X$, let $F_{x}=\left\{y \in Y: x \in \bar{V}_{y}\right\}$; then $F_{x}$ is finite, and $F_{x} \subset B_{\varepsilon}(\phi(x))$. Let $S=X-Z$, and for each $s \in S$ define

$$
G_{s}=\left\{x \in X: \operatorname{conv} F_{s} \subset B_{\varepsilon}(\phi(x))\right\}-\bigcup\left\{\bar{V}_{y}: y \notin F_{s}\right\} .
$$

Then $s \in G_{s}$ because $B_{\varepsilon}(\phi(s))$ is convex, and $G_{s}$ is open in $X$ because $\phi$ is l.s.c. and conv $F_{s}$ is compact (see [3, Lemma 11.3]). For later use, let us also note that $F_{x} \subset F_{s}$ for all $x \in G_{s}$.

Let $G=\mathrm{U}\left\{G_{s}: s \in S\right\}$, and let $E=X-G$. Then $E$ is closed in $X$ and $E \subset Z$, so $\operatorname{dim} E \leqq 0$. Hence the relatively open cover $\left\{V_{y} \cap E: y \in Y\right\}$ of $E$ has a relatively open, disjoint refinement $\left\{D_{y}: y \in Y\right\}^{4}$.

Let $W_{y}=V_{y} \cap\left(D_{y} \cup G\right)$. The $\left\{W_{y}: y \in Y\right\}$ is a locally finite, open cover of $X$, and thus has a partition of unity $\left\{p_{y}: y \in Y\right\}$ subordinated to it. Define

$$
f(x)=\sum_{y \in Y^{\prime}}\left(p_{y}(x)\right) y .
$$

Clearly $f$ is continuous, so we need only check that $f(x) \in B_{\varepsilon}(\dot{\phi}(x))$ for all $x \in X$.

If $x \in E$, the $f(x)=y \in B_{\varepsilon}(\phi(x))$ for the unique $y \in Y$ such that $x \in D_{y}$. So suppose that $x \in G$. Then $x \in G_{s}$ for some $s \in S$, so

$$
f(x) \in \operatorname{conv} F_{x} \subset \operatorname{conv} F_{s} \subset B_{\varepsilon}(\phi(x)) .
$$

That completes the proof.

REMARK. The above proof implies that $X$ need only be assumed normal and countably paracompact if $Y$ is separable, and that $X$ need only be normal if $\bigcup_{x \in X} \phi(x)$ is contained in a compact subset of $Y$.

\section{REFERENCES}

1. E. Michael, Selected selection theorems, Amer. Math. Monthly, 63 (1956), 233-238.

2. Continuous selections I, Ann. of Math., 63 (1956), 361-382.

3. - Continuous selections II, Ann. of Math., 64 (1956), 562-580.

Received May 21, 1979. The first author was supported in part by a National Science Foundation grant at the University of Washington, and in part by an Alexander von Humboldt Foundation grant at the University of Stuttgart.

UNIVERSITY OF WASHINGTON

SeAtTLE, WA 98195

AND

Southwest Texas State University

SAN MarCos, TX 78666

${ }^{4}$ This follows, for instance, from [1, Proposition 2]. 


\section{PACIFIC JOURNAL OF MATHEMATICS}

\section{EDITORS}

DONALD BABBITT (Managing Editor)

University of Galifornia

Los Angeles, California 90024

HUGo RossI

University of Utah

Salt Lake City, UT 84112

C. C. MOORE AND ANDREW OGG

University of California

Berkeley, CA 94720

\section{J. DUGUNDJI}

Department of Mathematics University of Southern California Los Angeles, California 90007

R. FINN AND J. MILGRAM Stanford University Stanford, California 94305

ASSOCIATE EDITORS
E. F. BECKENBACH
B. H. NeumanN
F. WoLF
K. YosHIDA

\section{SUPPORTING INSTITUTIONS}

UNIVERSITY OF BRITISH COLUMBIA UNIVERSITY OF SOUTHERN CALIFONIA CALIFORNIA INSTITUTE OF TECHNOLOGY UNIVERSITY OF CALIFORNIA MONTANA STATE UNIVERSITY STANFORD UNIVERSITY UNIVERSITY OF HAWAII UNIVERSITY OF TOKYO UNIVERSITY OF NEVADA, RENO UNIVERSITY OF UTAH NEW MEXICO STATE UNIVERSITY WASHINGTON STATE UNIVERSITY OREGON STATE UNIVERSITY UNIVERSITY OF OREGON UNIVERSITY OF WASHINGTON 


\section{Pacific Journal of Mathematics \\ Vol. 87, No. $1 \quad$ January, 1980}

Spiros Argyros, A decomposition of complete Boolean algebras ..........

Gerald A. Beer, The approximation of upper semicontinuous multifunctions

by step multifunctions . . . . ....................

Ehrhard Behrends and Richard Evans, Multiplicity theory for Boolean

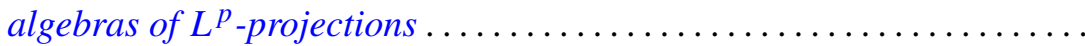

Man-Duen Choi, The full $C^{*}$-algebra of the free group on two

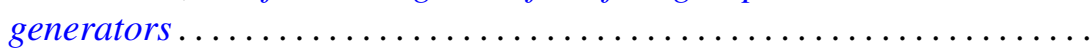

Jen-Chung Chuan, Axioms for closed left ideals in a $C^{*}$-algebra . . . . . . . .

Jo-Ann Deborah Cohen, The strong approximation theorem and locally

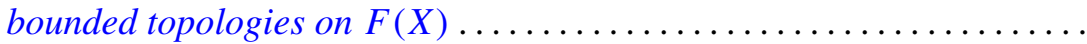

Eugene Harrison Gover and Mark Bernard Ramras, Increasing sequences of Betti numbers............................

Morton Edward Harris, Finite groups having an involution centralizer with

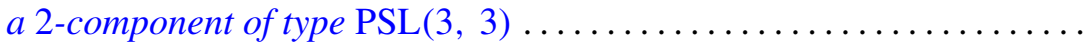

Valéria Botelho de Magalhães Iório, Hopf $C^{*}$-algebras and locally compact

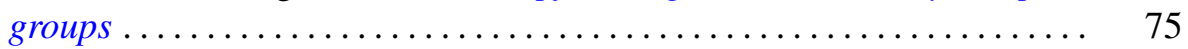

Roy Andrew Johnson, Nearly Borel sets and product measures . . . . . . . . . .

Lowell Edwin Jones, Construction of $Z_{p}$-actions on manifolds . . . . . . . . .

Manuel Lerman and Robert Irving Soare, $d$-simple sets, small sets, and

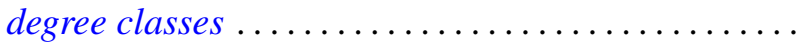

Philip W. McCartney, Neighborly bushes and the Radon-Nikodým property

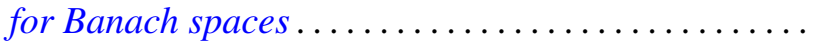

Robert Colman McOwen, Fredholm theory of partial differential equations on complete Riemannian manifolds.

Ernest A. Michael and Carl Preston Pixley, A unified theorem on continuous selections.

Ernest A. Michael, Continuous selections and finite-dimensional sets .

Vassili Nestoridis, Inner functions: noninvariant connected components...

Bun Wong, A maximum principle on Clifford torus and nonexistence of proper holomorphic map from the ball to polydisc.

Steve Wright, Similarity orbits of approximately finite $C^{*}$-algebras . . .

Kenjiro Yanagi, On some fixed point theorems for multivalued

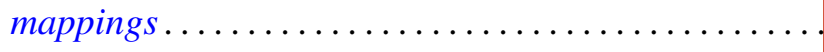

Wieslaw Zelazko, A characterization of LC-nonremovable ideals in commutative Banach algebras 